\title{
Cervical cytology external and internal quality assurance: a comparative appraisal
}

\author{
D N Slater
}

\section{Introduction}

The National Health Service Cervical Screening Programme (NHSCSP) requires purchasers to ensure that laboratories are participating in appropriate external quality assessment schemes. ${ }^{1}$ Laboratory providers must also show evidence in their business plans of active participation in both external and internal quality assurance programmes. ${ }^{2}$ However, little information is available on the comparative value of the different methods of quality assurance.

As Chairman of the Trent Regional Gynaecological Cytology External Quality Assessment Committee I am involved in the monitoring of cytoscreener performance. This article describes a series of events which permitted an appraisal of external and internal quality assurance methods. The findings are relevant to quality assurance in the NHSCSP. To maintain confidentiality, the cytopathology department is kept anonymous.

\section{Case Report}

Cytopathology department $\mathrm{X}$ is the main provider of the NHSCSP for one district in the Trent region. Its cytoscreener and checker workload/staff ratio conforms to the British Society for Clinical Cytology (BSCC) guidelines and the total number of slides screened per annum by the Laboratory is well above the recommended BSCC laboratory minimum. ${ }^{3}$ The environment for screening, although not perfect, is comparable with several other laboratories within the region. No undue pressure had been placed on staff when there have been backlogs in reporting time.

External quality assessment is achieved primarily by full participation in the Trent regional gynaecological cytology proficiency testing scheme, which is also part of the national scheme. The laboratory also participates in a local slide exchange external quality assessment scheme. Before 1993, internal quality control comprised the selected re-screening of high risk clinical categories, $10 \%$ random re-screening, double screening of diagnostic samples, and correlation between cytological and histopathological diagnoses. Since 1993, internal quality control has also included review of previous negative cytology smears from patients later presenting with at least moderate dys- karyosis. This extension of internal quality control was largely facilitated by earlier computerisation of the department.

Before 1993, there had been no perceived problems with either external or internal quality assurance and no member of staff had failed any round of the proficiency testing scheme. However, during 1993, it became increasingly evident from negative smear review that one cytoscreener (A) appeared to be particularly associated with the occurrence of false negative reports. Accordingly, a decision was made to review the accuracy of cytoscreener A's work by re-screening 500 consecutive cervical smears, previously reported as negative. All ongoing work of cytoscreener A was also to be checked until the potential problem had been assessed. The re-screening exercise was undertaken by two consultant cytopathologists, and one senior and three chief medical laboratory scientific officers. In general, with the exception of borderline changes, re-screened slides produced an excellent uniformity of opinion. It was therefore considered appropriate to evaluate the findings on the basis of missed inadequate smears and the false negative rate of missed dyskaryotic smears (table 1). Missed inadequate smears were expressed as a percentage of total rescreened smears and the false negative rate was calculated using the standard statistical definition. ${ }^{4}$ The number of previously reported abnormal smears, relating to the 500 review slides, was obtained from the laboratory computer. The identified false negative rate of $15 \%$, however, proved difficult to interpret in the absence of any published national standard for false negative rates in the NHSCSP. Therefore, the re-screening exercise was extended to include four additional cytoscreeners to permit further comparison. A period of illness during late 1991 may also have adversely affected the 1993 false negative rate. Accordingly,

Table 1 Percentage of missed inadequate rates and false negative rates

\begin{tabular}{lll}
\hline Cytoscreener & $\begin{array}{l}\text { Missed inadequate } \\
\text { rate (\%) }\end{array}$ & $\begin{array}{l}\text { False negative } \\
\text { rate (\%) }\end{array}$ \\
\hline A & & \\
1993 & 4 & 16 \\
1991 & 9 & 14 \\
B & 4 & 11 \\
D & 5 & 5 \\
E & 3 & 4 \\
\hline
\end{tabular}

Correspondence to: Dr D N Slater, 23 Redmires Road, Sheffield S10 4LA. 
Table 2 Results of cytoscreener $A$ before and after refresher course

\begin{tabular}{lll}
\hline Course & $\begin{array}{l}\text { False negative } \\
\text { rate (\%) }\end{array}$ & $\begin{array}{l}\text { False positive } \\
\text { rate (\%) }\end{array}$ \\
\hline Pre-refresher & 12 & 34 \\
Post-refresher & 3 & 13 \\
\hline
\end{tabular}

additional work from cytoscreener A, taken from early 1991, was re-screened (table 1).

A review of the literature suggested that the overall false negative rate of $15 \%$ for cytoscreener A, although high, was probably neither wholly unreasonable nor negligent. Compared with the other cytoscreeners in the department, however, the performance of cytoscreener A was probably marginal, but improvements in practice could be expected and attendance at a refresher course at a BSCC recognised training school (Sheffield Northern General Hospital) could be beneficial. Cytoscreener A had also received some in-house retraining, before attending the refresher course, which involved screening slide sets. Unknown to cytoscreener A, these sets had included all of the missed dyskaryotic smears from the re-screening exercise.

The slides were then renumbered and represented to cytoscreener $A$ on returning from the refresher course. The substantial improvement in false negative and false positive rates following the refresher course is shown in table 2. In view of this improvement cytoscreener A was allowed to return to unsupervised screening but with continued careful monitoring.

No deterioration in standards was noticed during the subsequent six months.

As a consequence of this experience, it seemed imperative to ascertain whether any other method of internal quality control could have detected or suggested the initial marginal screening performance by cytoscreener $\mathrm{A}$. The laboratory computer was therefore used to generate statistics relating to individual cytoscreeners. This included the number of slides screened per annum, pick-up rates, and referral rates to checkers of slides eventually reported as negative. The latter served as an indicator of slides referred by cytoscreeners to checkers for a second opinion. The results are shown in table 3 and relate to cytoscreeners all working on a 0.5 whole time equivalent basis and having a similar screening case-mix. The points of interest, with particular reference to cytoscreener $\mathrm{A}$, included the extremely low referral rate for a second opinion and the low pickup rate of borderline changes and mild dyskaryosis. It is of particular interest that cytoscreener A screened the largest number of slides per annum, although just within the BSCC guidelines. ${ }^{3}$ An inverse trend could also be seen between the overall pick-up rate and slides screened per annum. The validity of this approach is shown by comparing average cytoscreener performance with the corresponding KC61 return. Cytology department $\mathrm{X}$ has now incorporated previous negative slide review and the statistical analysis of cytoscreener work into its internal quality control procedures.

\section{Discussion}

It could be construed as unfortunate that the proficiency testing scheme failed to identify or suggest the possibility of marginal cytoscreener performance. Indeed, proficiency testing could therefore even be criticised for perhaps conveying a false impression of diagnostic accuracy and that no problems existed. However, continuing personal experience, as a regional chairman for the scheme, has convinced me that proficiency testing has an important role in the identification of overtly poor performance. Furthermore, proficiency testing also provides an important means to standardise interdistrict and inter-regional reporting practice. This case report, however, emphasises that no one method of quality assurance in the NHSCSP should be regarded as absolute and each, whenever possible, should be interpreted in the light of other methods.

Similarly, it is disappointing that several accepted standard methods of internal control also failed to identify or suggest marginal performance. There is, however, increasing agreement that $10 \%$ random re-screening is probably not a reliable method of internal quality control. ${ }^{5}$ A pilot study in the Trent region is currently assessing the value of $10 \%$ targeted rescreening and its ability, from rolling amalgamated data, to derive the false negative rate of individual cytoscreeners. The results of this study appear promising and will be published in the near future. An intriguing question is whether 30 second/rapid re-screening would have identified the marginal performance, but unfortunately, the study provided no information on this point. "The review of previous cytology when current cytological material shows unexpected abnormality" is a listed method of internal quality control in publications from both the BSCC and the Department of Health. ${ }^{367}$ However, there are

Table 3 Individual cytoscreener analysis

\begin{tabular}{|c|c|c|c|c|c|c|c|c|}
\hline Cytoscreener & $\begin{array}{l}\text { Negative } \\
\text { after checking }\end{array}$ & $\begin{array}{l}\text { Inadequate } \\
\text { smears }\end{array}$ & $\begin{array}{l}\text { Borderline } \\
\text { changes }\end{array}$ & $\begin{array}{l}\text { Mild } \\
\text { dyskaryosis }\end{array}$ & $\begin{array}{l}\text { Moderate } \\
\text { dyskaryosis }\end{array}$ & $\begin{array}{l}\text { Severe } \\
\text { dyskaryosis }\end{array}$ & $\begin{array}{l}\text { Total pick-up } \\
\text { rate }\end{array}$ & $\begin{array}{l}\text { Slides screened } \\
\text { per annum }\end{array}$ \\
\hline $\begin{array}{l}\text { A } \\
\text { B } \\
\text { C } \\
\text { D } \\
\text { E } \\
\text { F } \\
\text { Average } \\
\text { KC61 }\end{array}$ & $\begin{array}{r}1.0 \\
4.9 \\
2.7 \\
5.9 \\
15.0 \\
9.3 \\
6.5\end{array}$ & $\begin{array}{l}3 \cdot 0 \\
2 \cdot 6 \\
1 \cdot 8 \\
6 \cdot 3 \\
4 \cdot 9 \\
7 \cdot 8 \\
4 \cdot 4 \\
4 \cdot 6\end{array}$ & $\begin{array}{l}1 \cdot 3 \\
2 \cdot 2 \\
2 \cdot 0 \\
2 \cdot 9 \\
2 \cdot 3 \\
2 \cdot 3 \\
2 \cdot 2 \\
2 \cdot 2\end{array}$ & $\begin{array}{l}3 \cdot 9 \\
6 \cdot 3 \\
4 \cdot 1 \\
4 \cdot 5 \\
6 \cdot 3 \\
4 \cdot 8 \\
5 \cdot 0 \\
4 \cdot 6\end{array}$ & $\begin{array}{l}1.6 \\
1.5 \\
1.3 \\
0.9 \\
1.6 \\
0.9 \\
1.3 \\
1.4\end{array}$ & $\begin{array}{l}0.7 \\
0.9 \\
0.3 \\
0.4 \\
1.4 \\
0.6 \\
0.7 \\
0.6\end{array}$ & $\begin{array}{r}7 \cdot 5 \\
10 \cdot 9 \\
7 \cdot 7 \\
9 \cdot 0 \\
11 \cdot 6 \\
9 \cdot 0 \\
9 \cdot 3 \\
8 \cdot 9\end{array}$ & $\begin{array}{l}3491 \\
2805 \\
3480 \\
2901 \\
2463 \\
3043\end{array}$ \\
\hline
\end{tabular}

Results are expressed as per cent except slides screened per annum. Average results are compared with KC61 returns. 
guidelines on preferred options and, furthermore, all methods are implied to have a similar weighting. As a result of this experience, it would appear reasonable to suggest that all laboratories should practice negative smear review as an essential part of internal quality control. It also adds validity to recommendations that slides should be stored for at least 10 and preferably 20 years. $^{367}$

This case confirms that the statistical analysis of individual cytoscreener performance is a useful means of internal quality control, although to date the method has only been formally advocated in Scotland. ${ }^{8}$ It appears that use of this method would have identified the apparent reluctance of cytoscreener A to seek a second opinion and revealed her difficulties in recognising low grade nuclear abnormalities. As in another study ${ }^{9}$ no correlation was seen between the pick-up rate and the false negative rate, but intriguingly, the pick-up rate appeared to be increasingly compromised by workloads approaching the BSCC recommended maximum for cytoscreeners. ${ }^{3}$ This approach also permits a critical breakdown of a laboratory's performance, provided overall in its KC61 returns.

In the absence of any nationally agreed standards it proved extremely difficult to interpret the significance of cytoscreener A's false negative rate. Consequently, the published information relating to this area was reviewed and has been discussed in detail elsewhere. ${ }^{10}$ In summary, it appears that even the best NHSCSP laboratories may have difficulty in bettering a $3-5 \%$ false negative rate and that this range may include the so-called standard excellence. In comparison, it is possible that some laboratories in the United Kingdom are working with an overall false negative rate as low as $15 \%$ and that this may constitute the minimum acceptable standard. The main role of quality assurance is to ensure that a minimum acceptable standard is maintained and to pursue improvements in quality towards standards of excellence by means of audit and education. The latter point is particularly well illustrated by this case, where substantial improvement in performance was noted following attendance at a recognised refresher course. This fully supports Health Service guidelines that emphasise the necessity to have adequate regional facilities for updating medical and nonmedical laboratory staff. ${ }^{1}$

If national standards for false negative rates in gynaecological cytology are to be advocated, a decision will have to be made whether borderline changes should be incorporated into the calculation. With reference to cytoscreener A, the identification of borderline changes appeared to be a problem and possibly even more so than missed dyskaryosis. However, missed borderline changes had to be omitted from the false negative rate calculation as little consensus of opinion could be achieved between those rescreening the smears. The new national guidelines on borderline change ${ }^{11}$ may overcome these diagnostic problems and reduce inter- observer variation. However, it could be argued that the false negaive rate should only refer to missed "neoplastic" lesions and that borderline changes should be omitted.

Missed inadequate smears are an important cause of false negative laboratory reports and can have the same adverse consequences as missed dyskaryosis. ${ }^{12}$ The analysis of individual cytoscreener performance can identify low reporting rates of inadequate smears and the audit of missed inadequate smears constitutes a useful method of internal quality assurance. Despite national guidelines to define smear inadequacy, however, the average reporting rates between centres varies tremendously. Therefore, it is essential that screening of inadequate smears is included in External Quality Assessment schemes.

This report also highlights that, to date, there is no nationally agreed procedure to formally review the adequacy of cytoscreener performance. The 500 negative slide re-screen used in this assessment was chosen on the basis that this approach is used in the United States. ${ }^{13}$ The case also served as a reminder that the accuracy of previously reported work by an identified persistent poor performer remains an unresolved issue. The re-screening of gynaecological cytology smears can also have the unfortunate consequence of identifying abnormalities that necessitate the issuing of amended reports to both patients and general practitioners. In this case it is extremely fortunate that most of the patients had already undergone repeat testing.

The author thanks the Head of Department of the cytopathology department involved for permission to report this case. The author also thanks Mrs Eileen Hewer, Regional Facilitator for the Trent Regional gynaecological cytology proficiency testing scheme, for practical help in assessing this problem.

1 National Cervical Screening Programme. Health Service Guidance (93)41-1993.

2 The Health of the Nation. First steps for the NHS. NHS Management Executive, Department of Health. 1992:19.

3 Recommended code of practice for laboratories providing a cytopathology service. British Society for Clinical Cytology. 1986:1-21.

4 Guidelines for cytology procedures and reporting in breas cancer screening. NHS Breast Screening Programme. Publication 22. 1992:34-35.

5 Melamed MR. Presidential Address. Acta Cytol 1973;17: 285-8.

6 Protocol for an external quality assessment scheme in cytopathology. Department of Health. 1987:1-11.

7 Report of the intercollegiate working party on cervical cytology screening. Royal College of Obstetricians and Gynaecologists. Progress Press, 1987:35-55.

8 Report by Ad Hoc Group of the Histopathology SubCommittee of the Scientific Services in Scotland (The Strong Report). SOHHD, 1987.

9 Krieger P, Naryshkin S. Random rescreening of cytologic smears. A practical and effective component of quality assurance programs in both large and small cytology laboratories. Acta Cytol 1994;38:291-8.

10 Slater DN. Cervical cytology internal quality assurancewhat are the national standards? Cytopathology 1994;5: what are

11 National Coordinating Network (National Cervical Screening Programme), British Society for Clinical Cytology, and ing Programme), British Society for Clinical Cytology, and nuclear changes in cervical smears: Guidelines on their nuclear changes in cervical smears: Guidelines on their 92.

12 Slater DN, Milner PC, Radley H. Audit of deaths from cervical cancer: Proposal for an essential component of the National Screening Programme. F Clin Pathol 1994 47:27-8.

13 Gambino R. Pap regulations-a not-so-quality story. Lab Report 1991;13:1-4. 